\title{
Evaluation of growth and development of some varieties of tomato (Lycopersicon esculentum Mill) under nethouse conditions in Chau Doc
}

\author{
Chuong V. Nguyen
}

Faculty of Agriculture and Natural Resources, An Giang University, An Giang, Vietnam

\begin{abstract}
This study was carried out under nethouse conditions in Chau Doc city with 6 types of black tomatoes to select the potential ones suitable for the local ecological conditions. The objective of this research was to evaluate growth parameters, fruit quality, and adaptability characteristics of black tomato varieties under nethouse conditions in Chau Doc city. The results showed that some promising cultivars had an early harvest ranging from 90 days to 103 days such as Indigo Rose, Viagra Socolate, black Russia, Cherry Chocolte, Black Baron and Savior. All cultivars had a plant structure well adapted to the local nethouse conditions in Chau Doc city. Variety Cherry Chocolate gained the highest fruit setting with 203. Viagra Socolate, black Russia, Cherry Chocolte gained higher at over 4,0 tons $/ 1,000 \mathrm{~m}^{2}$. The lowest yield of the Black Baron was obtained at 2,83 tons $/ 1,000 \mathrm{~m}^{2}$. The Savior was obtained at 7.05 tons $/ 1,000 \mathrm{~m}^{2}$ with a relatively good fruit quality. Briefly, the promising cultivars are Viagra Socolate, Cherry Chocolte, black Russia and further research is needed to evaluate their real field production.
\end{abstract}

Nguyen Van Chuong

Email: nvchuong@agu.edu.vn

Cited as: Nguyen, C. V. (2019). Evaluation of growth and development of some varieties of tomato (Lycopersicon esculentum Mill) under nethouse conditions in Chau Doc. The Journal of Agriculture and Development 18(5), 10-17. 


\title{
Khảo sát khả năng sinh trưởng và phát triển của một số giống cà chua (Lycopersicon esculentum Mill) trong điều kiện nhà lưới tại Thành phố Châu Đốc
}

\author{
Nguyễn Văn Chương \\ Khoa Nông Nghiệp, Trường Đại Học An Giang, An Giang
}

\author{
THÔNG TIN BÀI BÁO \\ Bài báo khoa học \\ Ngày nhận: 19/12/2018 \\ Ngày chỉnh sửa: 06/09/2019 \\ Ngày chấp nhận: 16/09/2019 \\ Tù̀ khóa \\ Cà chua đen \\ Nhà lưới \\ Thành phố Châu Đốc \\ Tác giả liên hệ \\ Nguyễn Văn Chương \\ Email: nvchuong@agu.edu.vn
}

\section{TÓM TẮT}

Nghiên cứu được thực hiện tại Thành phố Châu Đốc trong điều kiện nhà lưới với 06 giống cà chua đen để chọn được giống cà chua phù hợp điều kiện sinh thái địa phương với mục tiêu đánh giá các chỉ tiêu sinh trưởng, phẩm chất trái và đặc tính thích nghi của các giống cà chua đen trong điều kiện nhà lưới tại TP. Châu Đốc. Kết quả nghiên cứu cho thấy 06 giống kết thúc thu hoạch gồm Indigo Rose, Viagra Socolate, Đen Nga, Cherry Chocolte, Baron Đen và Savior từ 90 đến 103 ngày. Tất cả các giống trong nghiên cứu có cấu trúc thân thích nghi tốt với điều kiện trong nhà lưới tại Châu Đốc. Tỷ lệ đậu quả của giống Cherry Chocolate cao nhất đạt 203 trái. Các giống Viagra Socolate, Đen Nga, Cherry Chocolte có năng suất thực thu cao trên 4 tấn $/ 1.000 \mathrm{~m}^{2}$, trong đó thấp nhất là Baron Đen chỉ đạt 2,83 tấn $/ 1.000 \mathrm{~m}^{2}$, cao nhất là Savior đạt 7,05 tấn $/ 1.000 \mathrm{~m}^{2}$ và chất lượng quả tương đối tốt. Tóm lại, các giống Viagra Socolate, Đen Nga, Cherry Chocolte cần được tiếp tục nghiên cứu trong các vụ mùa tiếp theo nhằm đánh giá tiềm năng của các giống này và áp dụng vào thực tế sản xuất.

\section{1. Đặt Vấn Đề}

Cà chua (Lycopersicon esculentum Mill) là loại rau ăn quả mang hiệu quả kinh tế và giá trị về dinh dưỡng cao, bên cạnh đó cà chua có ý nghĩa tích cực trong việc luân canh tăng vụ. Châu Đốc không trồng được cà chua, đến năm 2013 đã thành công với mô hình trồng cà chua ghép gốc. Đồng thời, việc áp dụng kỹ thuật ghép gốc cà tím giúp cây cà chua sinh trưởng và chống chịu với điều kiện ngoại cảnh cũng như áp lực sâu bệnh tốt hơn. Sau đó tiếp tục mở rộng diện tích trồng cà chua ghép và phát triển hơn nữa với mô hình trồng cà chua trong nhà màng với kỹ thuật trồng bán thủy canh trên giá thể, tưới nhỏ giọt tiếp tục cho kết quả khả quan. Trong năm 2015 và 2016, nông dân đã tiến hành trồng thử giống cà chua đen kết quả nhận được rất khả quan, cây trồng phát triển tốt, giá cao hơn so với cà chua thường. Cà chua đen là loại cây trồng cho giá trị sản xuất và thành phần dinh dưỡng cao với hàm lượng vitamin và chất chống oxi hóa rất cao, chứa anthocyanin, chất chống oxy hóa có trong quả việt quất (Dang \& ctv., 2009). Đồng thời, anthocyanin cũng là thành phần không thể thiếu trong các loại thực phẩm chức năng và thực phẩm khác, điều đó hoàn toàn phù hợp với xu hướng hiện nay của các nước trên thế giới là nghiên cứu khai thác tính ưu việt của các hợp chất từ thiên nhiên phục vụ cho các nhu cầu nâng cao cuộc sống của con người. Do vậy, mục tiêu nghiên cứu nhằm đánh giá các chỉ tiêu sinh trưởng, phẩm chất trái và đặc tính thích nghi của các giống cà chua đen trong điều kiện nhà lưới tại TP. Châu Đốc, tỉnh An Giang.

\section{Vật Liệu và Phương Pháp Nghiên Cứu}

\subsection{Vật liệu}

Thí nghiệm được tiến hành trong nhà lưới vụ Hè Thu từ tháng $5 / 2017$ dến tháng $9 / 2017$, tại phường Châu Phú $\mathrm{B}$, TP. Châu Đốc, tỉnh An Giang.

Sáu giống cà chua đen: Indigo Rose, Viagra Socolate, Đen Nga, Cherry Chocolte, Baron Đen và Savior (giống do công ty Syngenta Việt Nam 
phân phối) được ghép gốc cà tím EG 203 chịu úng và chịu hạn tốt của Trung tâm Nghiên cứu và phát triển Châu Á (AVRDC).

Giá thể trồng: được phối trộn hỗn hợp tro trấu, trấu sống, xơ dừa, phân hữu cơ ủ oai, phân hữu cơ vi sinh, phân lân tî̉ lệ 30:10:30:10:5:2,5 (\%) và nấm Trichoderma.

Chậu nhựa đường kính $40 \mathrm{~cm}$.

Hệ thống ống tưới nhỏ giọt kêt hợp tưới nước với dinh dưỡng (Công ty Khang Thịnh). Dinh dưỡng sẽ được pha vào nước, phối hợp tưới nước và bón phân vào các đợt bón. Giai đoạn mới trồng không sử dụng nhiều phân đạm và chất kích thích sinh trưởng dễ làm hở, bung vết ghép. Phân bón và nông dược: $0-52-34,12-61-0, \mathrm{~K}_{2} \mathrm{SO}_{4}$, hữu cơ 5.4.3, Mg, Ca, Zn, Bo, Super Cal 8, Tomato Plus, Obaone $90 \mathrm{WG}$, Chess, Close, Prevathone, Benivia, Tricoderma, phối hợp chất bám dính khi phun thuốc bệnh và dầu khoáng khi phun thuốc trừ sâu, rầy.

\subsection{Phương pháp}

\subsubsection{Bố trí thí nghiệm}

Thí nghiệm được bố trí theo thể thức khối hoàn toàn ngẫu nhiên theo chiều biến động ánh sáng bao gồm 6 nghiệm thức, mỗi nghiệm thức là 1 giống cà chua đen và 1 nghiệm thức làm đối chứng (Savior). Mỗi nghiệm thức có 6 chậu (cây), 4 lần lạ̣p lại. Các nghiệm thức gồm NT1: Cà chua đen Indigo Rose, NT2: Cà chua Viagra Socolate, NT3: Cà chua Đen Nga, NT4: Cà chua Cherry Chocolate, NT5: Cà chua Baron đen, NTĐC: Cà chua Savior. Khoảng cách trồng bố trí các túi cách túi $40 \mathrm{~cm}$, hàng cách hàng $80 \mathrm{~cm}$. Mật độ 3.000 chậu/1.000 m². Mỗi nghiệm thức $2 \mathrm{~m}^{2}$ (6 chậu). Diện tích thí nghiệm: $2 \mathrm{~m}^{2} \times 6 \mathrm{NT} \times 4=48 \mathrm{~m}^{2}$.

\subsubsection{Kỹ thuật canh tác}

Chuẩn bị cây con: Gốc ghép cà tím EG 203 được gieo trước 3 - 7 ngày. Ngọn ghép cà chua đen gieo trên khay với giá thể hỗn hợp mụn xơ dừa và phân hữu cơ vi sinh, tỉ lệ 10:0,5 trộn đều, tưới thật ẩm. Khi cây cao $10 \mathrm{~cm}-15 \mathrm{~cm}$, có 4 - 6 lá thật đối với gốc cà tím và cao $15 \mathrm{~cm}$ - 18 cm đối với ngọn cà đen, cây cứng cáp, không sâu bệnh, đường kính gốc và ngọn tương đương nhau thì tiến hành ghép. Khoảng 12 - 15 ngày sau khi ghép, cây khỏe mạnh, không sâu bệnh, liền vết ghép là đủ tiêu chuẩn để trồng.
Trồng cây ghép: Trồng vào buổi chiều mát, vết ghép phải nằm trên mặt đất, cố định cây ghép tránh làm tổn thương vết ghép. Tỉa bỏ các chồi của ngọn ghép khi vừa nhú ra, mỗi cây chỉ để lại 1 thân chính và 2 nhánh cấp 1 ở sát dưới chùm hoa thứ nhất, sau đó để cây ra nhiều nhánh sẽ cho nhiều hoa. Tiến hành làm giàn sau khi trồng $2-3$ tuần, cây cao $30 \mathrm{~cm}-40 \mathrm{~cm}$.

Bón phân: Phân bón sẽ được pha vào nước, phối hợp tưới nước và bón phân vào các đợt bón. Giai đoạn mới trồng không sử dụng nhiều phân đạm và chất kích thích sinh trưởng dễ làm hở, bung vết ghép. Lượng phân bó được trình bày trong Bảng 1.

\subsubsection{Các chỉ tiêu theo dõi}

Các chỉ tiêu theo dõi gồm: Thời gian sinh trưởng của các giống cà chua; chiều cao cây $(\mathrm{cm})$ : đo dọc theo thân chính từ cổ rể đến đỉnh sinh trưởng của cây; thành phần năng suất: Số trái trên cây được xác định bằng cách đếm số trái trên từng cây qua tất cả các lần thu hoạch rồi cộng tổng; trọng lượng trái trên cây $(\mathrm{kg} /$ cây $)$ : Cân tất cả trái của từng cây ở các lần thu hoạch, rồi cộng tổng; phẩm chất trái: Độ khác màu vỏ trái và hàm lượng Anthocyanin trong trái, hàm lượng vitamin C thịt trái $(\mathrm{mg} / 100 \mathrm{~g})$.

\subsubsection{Phương pháp phân tích}

Màu vỏ trái được đo bằng máy đo màu Chroma Meter CR - 400, đo ở vị trí đầu, giữa và ở cuối trái. Hàm Lượng Anthocyanin trong trái được đo bằng phương pháp $\mathrm{pH}$ vi sai. Hàm lượng vitamin C thịt trái $(\mathrm{mg} / 100 \mathrm{~g})$ được đo bằng phương pháp xác định hàm lượng vitamin $\mathrm{C}$ (Axit Ascobic) theo tiêu chuẩn Việt Nam - TCVN 4715:1989.

\subsection{Phương pháp xử lý số liệu}

Sử dụng chương trình Microsoft Excel nhập liệu, vẽ đồ thị và phần mềm MSTASC để thống kề và phân tích số liệu.

\section{Kết Quả và Thảo Luận}

\subsection{Thời gian sinh trưởng của các giống cà chua}

Kết quả Bảng 2, thời gian từ khi trồng đến trổ hoa của các giống không cách nhau nhiều. Hai giống Cherry Chocolate và Savior trổ hoa sớm 
Bảng 1. Lượng phân bón $\left(1.000 \mathrm{~m}^{2}\right)$

\begin{tabular}{|c|c|c|c|c|c|c|c|}
\hline \multirow{2}{*}{ Loại phân } & \multirow{2}{*}{ Tổng số } & \multirow{2}{*}{ Giá thể } & \multicolumn{5}{|c|}{ Dinh dưỡng ngày sau trồng } \\
\hline & & & $0-15$ & $15-30$ & $30-45$ & $45-75$ & $75-105$ \\
\hline Borat $(\mathrm{kg})$ & 0,5 & 0,5 & - & - & - & - & - \\
\hline Tricoderma (lít) & 16 & 16 & - & - & - & - & - \\
\hline $12-6-0(\mathrm{~kg})$ & 38 & - & \multicolumn{3}{|c|}{ Cách ngày/lần } & - & - \\
\hline $0-52-34(\mathrm{~kg})$ & 44 & - & \multicolumn{3}{|c|}{ Cách ngày/lần } & - & - \\
\hline $\mathrm{K}_{2} \mathrm{SO}_{4}(\mathrm{~kg})$ & 36 & - & - & - & - & \multicolumn{2}{|c|}{ Cách ngày/lần } \\
\hline HC 5.4.3 (lít) & 10 & - & - & - & - & \multicolumn{2}{|c|}{ Cách ngày/lần } \\
\hline $\operatorname{Mg}(\mathrm{kg})$ & 40 & - & \multicolumn{5}{|c|}{ Cách ngày/lần } \\
\hline $\mathrm{Ca}(\mathrm{kg})$ & 30 & - & \multicolumn{5}{|c|}{ Cách ngày/lần } \\
\hline Phân bón trung, vi & & & \multirow{2}{*}{\multicolumn{5}{|c|}{$\begin{array}{c}2 \text { - } 3 \text { ngày } 1 \text { lần tùy nhu cầu dinh dưỡng } \\
\text { từng giai doạn }\end{array}$}} \\
\hline lượng (Zn, Bo) (g) & 13 & - & & & & & \\
\hline Super Cal 8 (lít) & 1 & - & & - & - & \multicolumn{2}{|c|}{7 ngày/lần phun trái } \\
\hline Tomato Plus (lít) & 0,5 & - & & - & - & \multicolumn{2}{|c|}{7 ngày/lần phun lá } \\
\hline
\end{tabular}

Bảng 2. Thời gian trổ, thu hoạch, kéo dài và kết thúc thu hoạch của giống cà chua tại nhà lưới Tp. Châu Đốc, tỉnh An Giang

\begin{tabular}{|c|c|c|c|c|}
\hline \multirow{2}{*}{ Giống } & \multicolumn{3}{|c|}{ Thời gian sau khi trồng (ngày) } & \multirow{2}{*}{$\begin{array}{l}\text { Thời gian kéo } \\
\text { dài thu hoạch } \\
\text { (ngày) }\end{array}$} \\
\hline & Trổ hoa & $\begin{array}{l}\text { Bắt đầu } \\
\text { thu hoạch }\end{array}$ & $\begin{array}{l}\text { Kết thúc } \\
\text { thu hoạch }\end{array}$ & \\
\hline Indigo Rose & 23 & 45 & 103 & 58 \\
\hline Viagra Socolate & 21 & 50 & 105 & 55 \\
\hline Đen Nga & 23 & 50 & 95 & 45 \\
\hline Cherry Chocolte & 19 & 52 & 97 & 45 \\
\hline Baron Đen & 22 & 60 & 90 & 30 \\
\hline Savior & 19 & 45 & 105 & 60 \\
\hline
\end{tabular}

(19 NSKT), kế đó là giống Viagra (21 NSKT), trễ nhất là 2 giống Indigo Rose và Đen Nga (23 NSKT).

Thời gian thu hoạch sớm nhất là giống Indigo Rose và Savior (45 NSKT), các giống còn lại có thời gian thu trái muộn hơn từ 50 - 60 NSKT. Riêng giống Baron Đen phải thực hiện biện pháp rung cây vào buổi sáng để hỗ trợ thụ phấn.

Mặc dù được trồng trong điều kiện kỹ thuật canh tác giống nhau nhưng thời gian kéo dài, thu hoạch không giống nhau giữa các giống. Thời gian thu hoạch dài nhất là giống Savior (60 ngày), kế đến là giống Indigo Rose (58 ngày), giống Baron Đen có thời gian thu hoạch ngắn nhất (30 ngày), thời gian thu hoạch có thể do đặc tính di truyền của giống và khả năng thích nghi với điều kiện ngoại cảnh.

Các giống khảo nghiệm hầu hết là giống nhập nội từ Nga và $M y ̃$ nên so về điều kiện khí hậu tại Việt Nam có phần khác biệt nhiều đặc biệt là nhiệt độ. Đây có thể là nguyên nhân ảnh hưởng đến sinh trưởng và phát triển của cây trồng.

\subsection{Chiều cao thân chính}

Kết quả Hình 1 cho thấy trong thời gian khảo sát chiều cao thân chính của các giống cà chua trồng trong nhà lưới qua các giai đoạn có sự khác biệt thống kê ở mức ý nghĩa 1\%, giống Cherry Chocolate có chiều cao thấp nhất tại giai đoạn 15 NSKT là $20,8 \mathrm{~cm}$ nhưng lại cao nhất ở giai đoạn 105 NSKT $(199 \mathrm{~cm})$, kế đến là giống Viagra $(173 \mathrm{~cm})$ và giống Indigo Rose $(141 \mathrm{~cm})$. Giống Đen Nga có chiều cao thấp nhất $(120 \mathrm{~cm})$. Tốc độ tăng trưởng chiều cao thân chính của các giống cà có khác nhau qua từng giai đoạn. Giống Cherry Chocole tăng trưởng mạnh nhất từ giai đoạn 15 - 60 ngày $(3,61 \mathrm{~cm} /$ ngày - 3,97 $\mathrm{cm} /$ ngày $-3,11 \mathrm{~cm} /$ ngày), kế đến là Viagra. Giai đoạn 30 - 45 NSKT là giai đoạn các giống có tốc độ tăng trưởng mạnh nhất $(2,11 \mathrm{~cm} /$ ngày - 3,97 $\mathrm{cm} / \mathrm{ngày})$. Từ giai đoạn $45 \mathrm{NSKT}$ về sau hầu hết các giống tăng trưởng chậm dần và chậm nhất ở giai đoạn 75 - 105 NSKT gần như không đáng kể $(0,03 \mathrm{~cm} /$ ngày $-0,12 \mathrm{~cm} /$ ngày $)$, giai đoạn này chủ yếu cung cấp dinh dưỡng để kết trái và nuôi trái. 


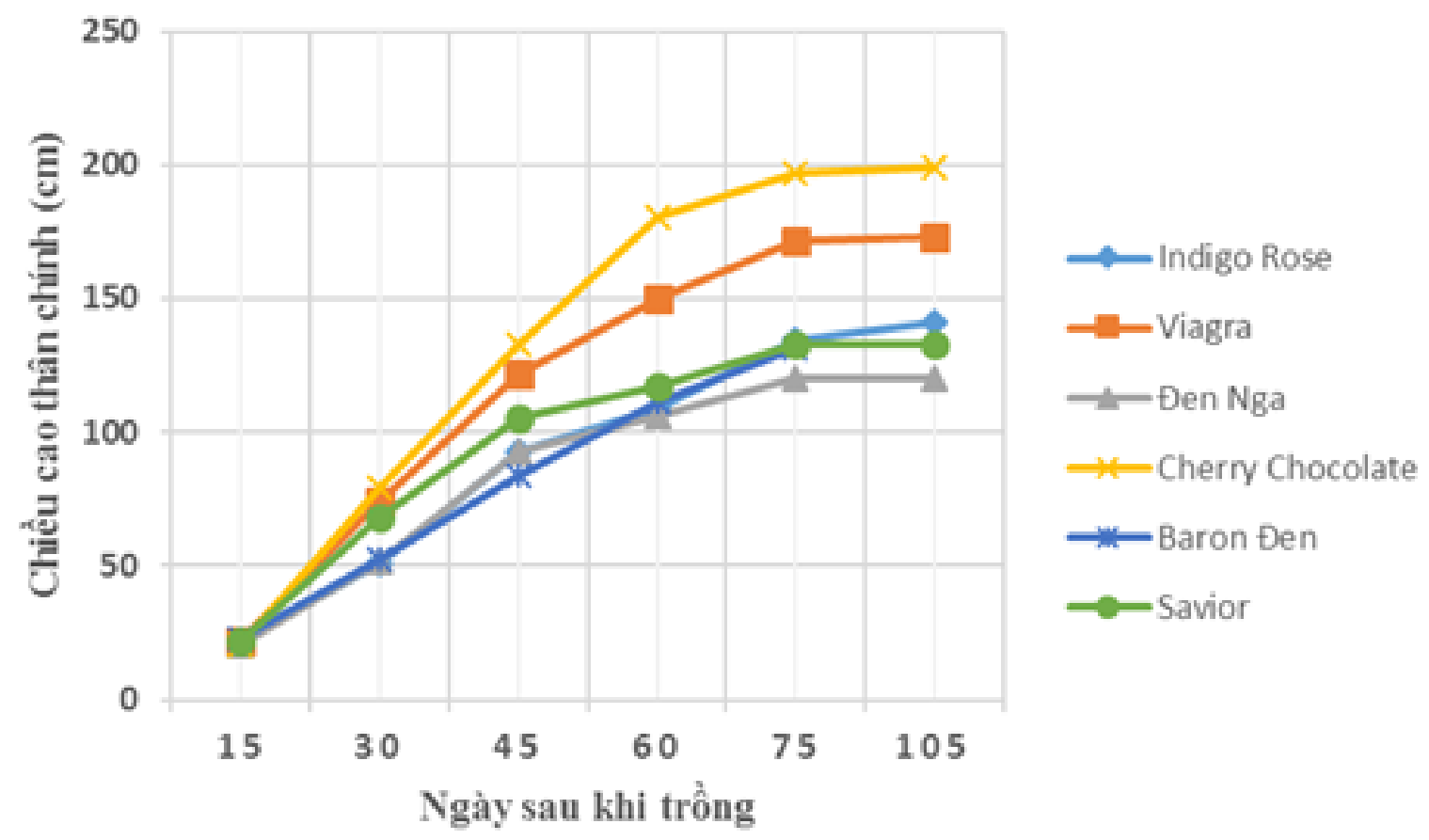

Hình 1. Chiều cao thân chính của 6 giống cà chua tại nhà lưới TP. Châu Đốc, tỉnh An Giang (Tháng 05 $09 / 2017)$.

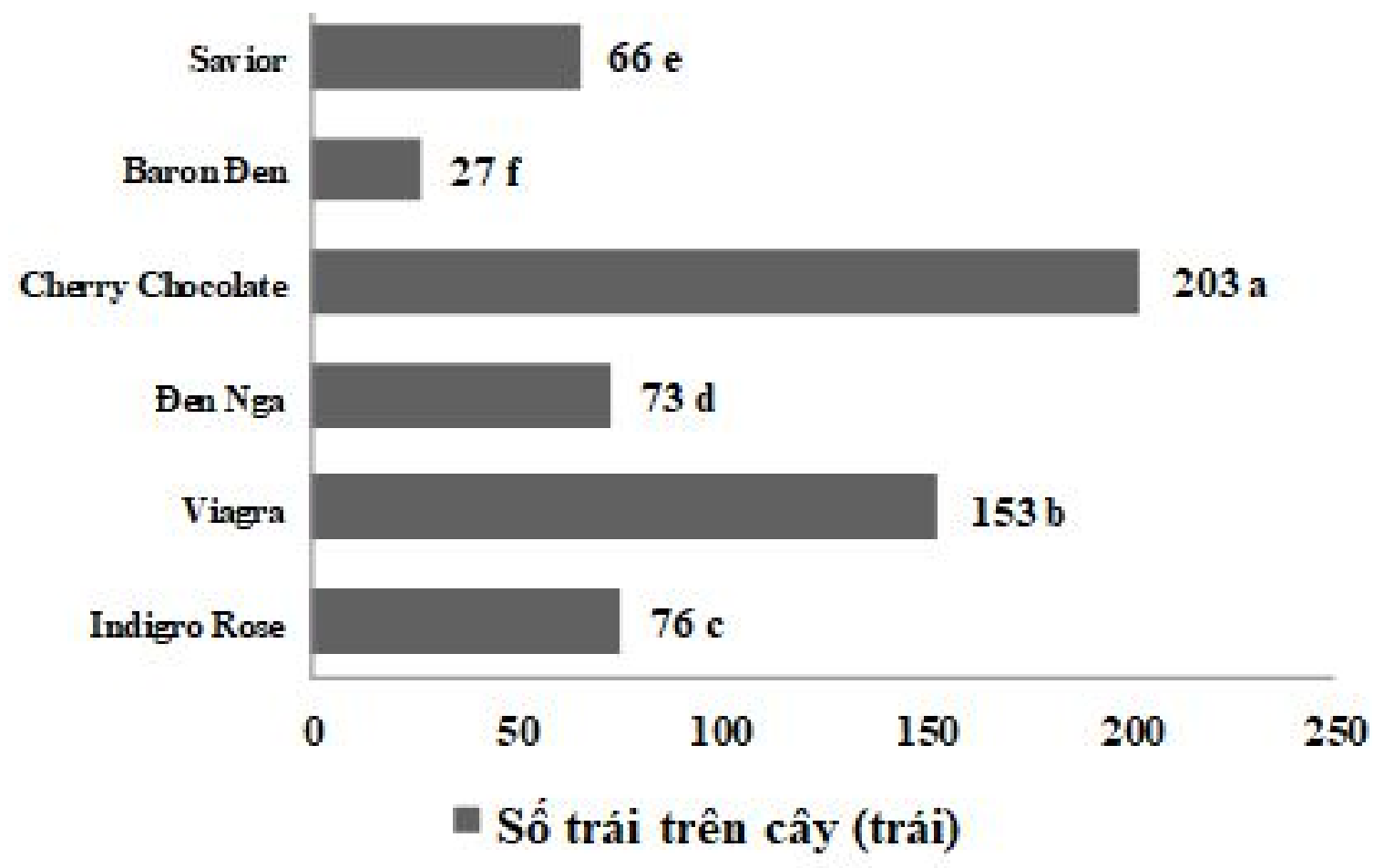

Hình 2. Số trái trên cây của 6 giống cà chua tại nhà màng (Châu Đốc, 05 - 09/2017). 
Bảng 3. Trọng lượng trái trên cây và năng suất của 6 giống cà chua tại nhà lưới

\begin{tabular}{lcc}
\hline Giống & $\begin{array}{c}\text { TL trái/cây } \\
(\mathrm{kg} / \text { cây })\end{array}$ & $\begin{array}{c}\text { Năng suất } \\
\left(\text { tấn } / 1.000 \mathrm{~m}^{2}\right)\end{array}$ \\
\hline Indigo Rose & $1,89^{\mathrm{b}}$ & $5,66^{\mathrm{b}}$ \\
Viagra & $1,47^{\mathrm{c}}$ & $4,42^{\mathrm{c}}$ \\
Đen Nga & $1,68^{\mathrm{bc}}$ & $5,03^{\mathrm{bc}}$ \\
Cherry Chocolate & $1,71^{\mathrm{b}}$ & $5,14^{\mathrm{b}}$ \\
Baron Đen & $0,94^{\mathrm{d}}$ & $2,83^{\mathrm{d}}$ \\
Savior & $2,35^{\mathrm{a}}$ & $7,05^{\mathrm{a}}$ \\
F & $* *$ & $* *$ \\
\hline CV $(\%)$ & 9,38 & 9,39 \\
\hline
\end{tabular}

${ }^{\mathrm{a}-\mathrm{d}}$ Các số trong cùng cột có chữ số theo sau giống nhau thì không có khác biệt qua phân tích Ducan; ** Khác biệt mức ý nghĩa $1 \%$.

Bảng 4. Độ khác màu vỏ trái và hàm lượng anthocyanin của 6 giống cà chua trồng tại nhà lưới (Châu Đốc, 05 - 09/2017)

\begin{tabular}{lcc}
\hline Giống & Độ khác màu vỏ trái & Anthocyanin $(\mu \mathrm{g} / \mathrm{kg})$ \\
\hline Indigo Rose & 30,7 & 1,70 \\
Viagra & 32,9 & 1,50 \\
Đen Nga & 29,5 & 1,70 \\
Cherry Chocolate & 31,0 & 1,10 \\
Baron Đen & 29,7 & 1,90 \\
Savior & 35,1 & 1,40 \\
$\mathrm{~F}^{1}$ & $\mathrm{~ns}$ & $\mathrm{~ns}$ \\
\hline $\mathrm{CV}(\%)$ & 11,5 & 12,9 \\
\hline
\end{tabular}

${ }^{1}$ ns: khác biệt không có ý nghĩa thống kê $(P>0,05)$.

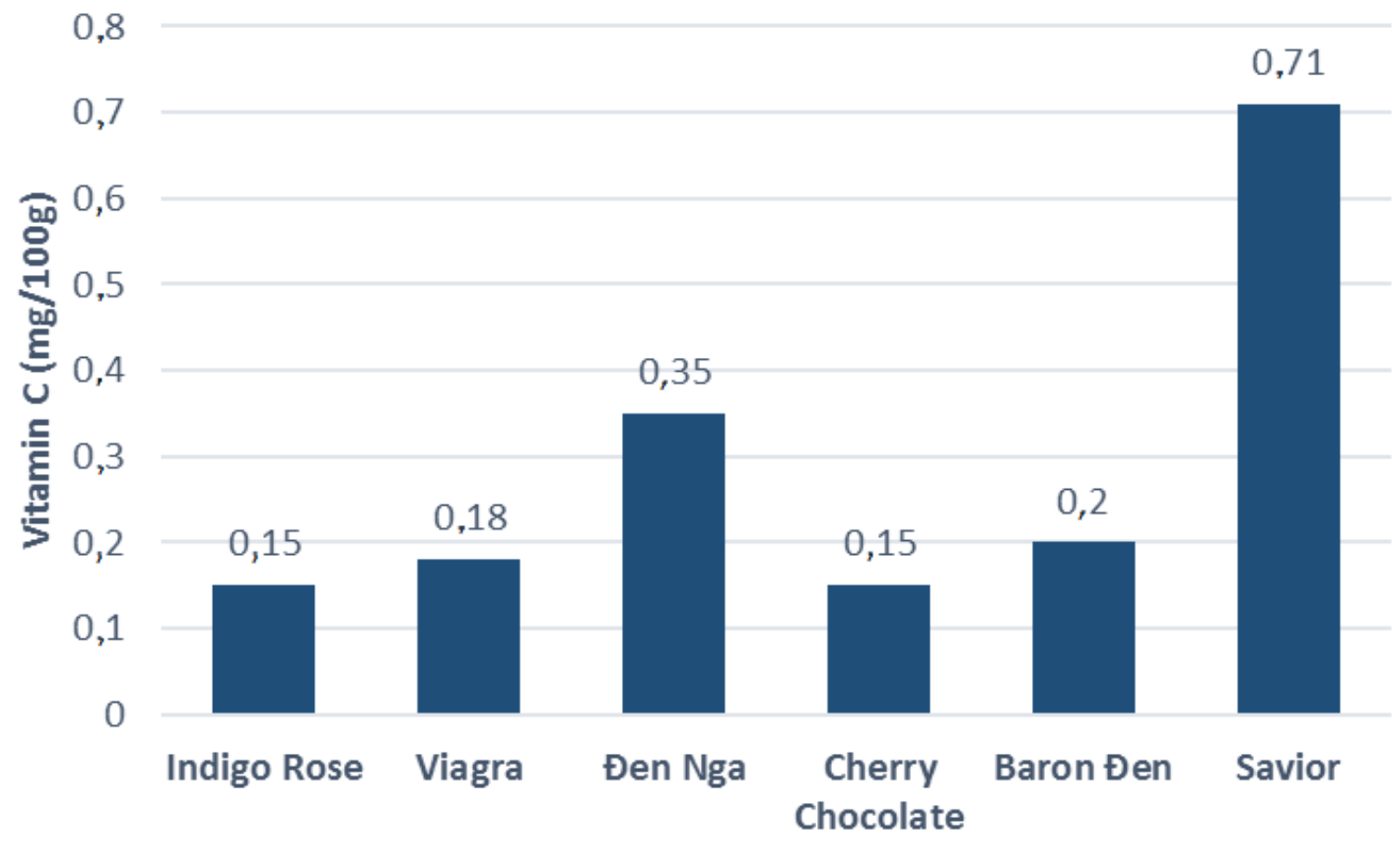

Hình 3. Hàm lượng Vitamin C của 6 giống cà tại nhà lưới (Châu Đốc, 05 - 09/2017). 
Giai đoạn đầu khi cây mới vào nhà (1 - 15 NSKT) cây có biểu hiện lá xoăn và vàng nhẹ nhưng sau đó lại ổn định trở lại, đến giai đoạn 30 - 45 NSKT cây có bộ rễ đã phát triển lại và đã dần thích nghi vời điều kiện bên trong nhà nên sinh trưởng nhanh.

\subsection{Thành phần năng suất}

\subsubsection{Số trái trên cây}

Kết quả Hình 2 cho thấy, tổng số trái trên cây của 6 giống cà chua có sự khác biệt thống kê mức ý nghĩa 1\%, giống Cherry Chocolate cho số trái trên cây cao nhất (203 trái) và giống Baron Đen có số trái trên cây thấp nhất (27 trái). Trong khi giống Savior có số trái trên cây thấp (66 trái) đứng vị trí thứ 2 về mặt thống kê. Điều này phù hợp với nghiên cứu của Ta (2005), số lượng trái trên cây phụ thuộc vào đặc tính di truyền của giống và tương quan chặt với năng suất. Đồng thời, cũng chịu tác động lớn của điều kiện ngoại cảnh và kỹ thuật canh tác.

\subsubsection{Trọng lượng trái trên cây}

Kết quả từ Bảng 3 cho thấy trọng lượng trái trên cây của 6 giống cà chua có sự khác biệt thống kê ở mức ý nghĩa 1\%, cao nhất là giống Savior $(2,35 \mathrm{~kg} /$ cây $)$ và thấp nhất là giống Baron Đen $(0,940 \mathrm{~kg} /$ cây $), 2$ giống Indigo Rose và Cherry Chocolate có trọng lượng trái lần lược là 1,89 $\mathrm{kg} /$ cây và $1,71 \mathrm{~kg} /$ cây đứng vị trí thứ 2 và không khác biệt. Giống Savior có số trái trên cây ít nhưng có trọng lượng trung bình trái lại cao $(33,1$ $\mathrm{g} /$ trái) điều này làm cho giống Savior đạt trọng lượng trái cao nhất. Năng suất của 6 giống cà chua có sự khác biệt thống kê ở mức ý nghĩa $1 \%$ cao nhất là giống Savior $\left(7,05\right.$ tấn $\left./ 1.000 \mathrm{~m}^{2}\right)$, thấp nhất là giống Baron Đen $(2,83$ tấn/1.000 $\mathrm{m}^{2}$ ). Giống Indigo Rose và Cherry Chocolate cho năng suất lần lược là 5,66 tấn $/ 1.000 \mathrm{~m}^{2}$ và 5,14 tấn $/ 1.000 \mathrm{~m}^{2}$ không khác biệt, trái lên màu đẹp về cảm quan, rất được người tiêu dùng ưa thích.

\subsection{Phẩm chất trái}

\subsubsection{Hàm lượng Vitamin C (mg/100 g)}

Hàm lượng vitamin $\mathrm{C}$ có sự khác biệt thống kê ở mức ý nghĩa 1\% (Hình 3). Giống Savior có hàm lượng vitamin $\mathrm{C}$ cao nhất $(0,71 \mathrm{mg} / 100 \mathrm{~g})$, giống Indigo Rose có hàm lượng vitamin $\mathrm{C}$ thấp nhất và tương đương với Cherry Chocolate $(0,15 \mathrm{mg} / 100$ g). Các giống còn lại có hàm lượng vitamin $\mathrm{C}$ lần lượt là $0,18 \mathrm{mg} / 100 \mathrm{~g}-0,2$ và $0,35 \mathrm{mg} / 100 \mathrm{~g}$. Theo Ta (2005), hàm lượng vitamin $\mathrm{C}$ được qui định bởi đặc tính giống.

\subsection{2. Độ khác màu vỏ trái và hàm lượng antho- cyanin}

Màu sắc quả là yếu tố quyết định trực tiếp đến giá trị thương phẩm và là đặc trưng của giống nhưng cũng chịu tác động mạnh của điều kiện ngoại cảnh, đặc biệt là ánh sáng và nhiệt độ không khí.

Màu sắc vỏ trái của 6 giống không có sự khác biệt thống kê. Nhìn chung, màu sắc vỏ trái của 6 giống cà chua có 3 màu: vỏ trái màu đỏ (giống Savior và Viagra), vỏ trái màu nâu (chocolate) là giống Cherry Chocolate và màu nâu đen ở 3 giống Indigo Rose, Đen nga và Baron Đen. Theo $\mathrm{Ta}(2002)$ sắc tố hình thành ở nhiệt độ $20^{\circ} \mathrm{C}$, màu sắc quả là đặc trưng của giống.

Kết quả từ Bảng 4 cho thấy trong trong các giống khảo sát có chứa một lượng anthocyanin mặc dù hàm lượng không cao và không có sự khác biệt thống kê, dao động từ $1,1 \mu \mathrm{g} / \mathrm{kg}-1,9$ $\mu \mathrm{g} / \mathrm{kg}$. Theo Dai (2008), anthocyanin là hợp chất màu hữu cơ có nguồn gốc tự nhiên, thuộc nhóm flavonoid, có màu đỏ, đỏ tía.

\section{Kết Luận}

Kết quả nghiên cứu cho thấy 06 giống kết thúc thu hoạch gồm Indigo Rose, Viagra Socolate, Đen Nga, Cherry Chocolte, Baron Đen và Savior từ 90 dến 103 ngày. Tỷ lệ đậu quả của giống Cherry Chocolate cao nhất đạt 203 trái. Các giống Viagra Socolate, Đen Nga, Cherry Chocolte có năng suất thực thu cao trên 4 tấn $/ 1.000 \mathrm{~m}^{2}$, trong đó thấp nhất là Baron Đen chỉ đạt 2,83 tấn/1.000 $\mathrm{m}^{2}$, cao nhất là Savior đạt 7,05 tấn $/ 1.000 \mathrm{~m}^{2}$ và chất lượng quả tương đối tốt. Sáu giống khảo sát có chứa một lượng anthocyanin dao động từ 1,1 $\mu \mathrm{g} / \mathrm{kg}-1,9 \mu \mathrm{g} / \mathrm{kg}$. Các giống triển vọng là Viagra Socolate, Đen Nga, Cherry Chocolte cần tiếp tục nghiên cứu các giống triển vọng được đề xuất trong các vụ mùa tiếp theo nhằm đánh giá tốt tiềm năng của các giống và áp dụng vào thực tế sản xuất.

\section{Tài Liệu Tham Khảo (References)}

Dai, B. D. (2008). Natural bioactive compounds used for preventing some diseases in human and animals. Ha 
Noi, Vietnam: Science and Technics Publising House.

Dang, T. T., To, A. K., Le, H. Q., Do, L. N., Nguyen, S. T. X., Le, T. N., \& Do, V. H. (2009). Basic biotechnology. T2 - Biochemical technology. Ha Noi, Vietnam: Vietnam Education Publishing House.
Ta, C. T. (2005). Lectures: Techniques for growing vegetables. Ha Noi, Vietnam: Ha Noi Publishing House.

Ta, C. T. (2002). Techniques for growing tomatoes. Ha Noi, Vietnam: Agricultural Publishing House. 